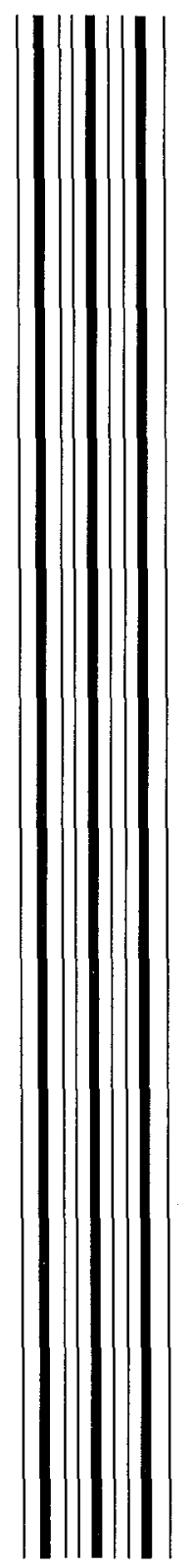

Preprint

UCRL-JC-131572

\title{
Electrical Resistance Tomography Using Steel Cased Boreholes as Electrodes
}

R.L. Newmark, W. Daily and A. Ramirez

This article was submitted to

Society of Exploration Geophysicists International Exposition and $69^{\text {th }}$ Annual Meeting Houston, TX

October 31-November 5, 1999

U.S. Department of Energy

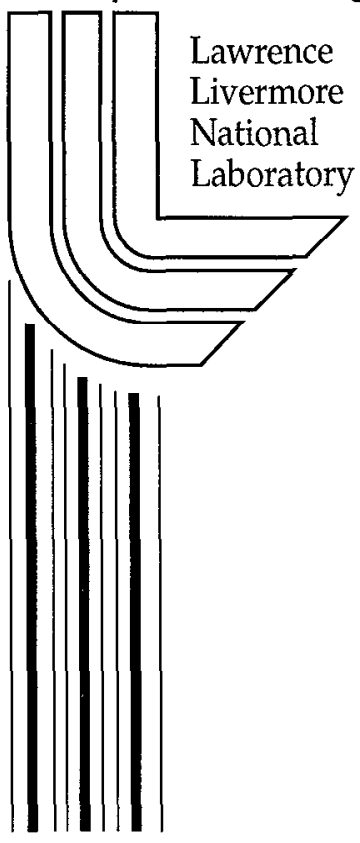

March 22, 1999 


\section{DISCLAIMER}

This document was prepared as an account of work sponsored by an agency of the United States Government. Neither the United States Government nor the University of California nor any of their employees, makes any warranty, express or implied, or assumes any legal liability or responsibility for the accuracy, completeness, or usefulness of any information, apparatus, product, or process disclosed, or represents that its use would not infringe privately owned rights. Reference herein to any specific commercial product, process, or service by trade name, trademark, manufacturer, or otherwise, does nol necessarily constitute or imply its endorsement, recommendation, or favoring by the United States Government or the University of California. The views and opinions of authors expressed herein do not necessarily state or reflect those of the United States Government or the University of California, and shall not be used for advertising or product endorsement purposes.

This is a preprint of a paper intended for publication in a journal or proceedings. Since changes may be made before publication, this preprint is made available with the understanding that it will not be cited or reproduced without the permission of the author.

This report has been reproduced directly from the best available copy.

Available to DOE and DOE contractors from the

Office of Scientific and Technical Information

P.O. Box 62, Oak Ridge, TN 37831

Prices available from (423) 576-8401

http://apollo.osti.gov/bridge/

Available to the public from the National Technical Information Service

U.S. Department of Commerce 5285 Port Royal Rd., Springfield, VA 22161 http://www.ntis.gov/

OR

Lawrence Livermore National Laboratory

Technical Information Department's Digital Library

http://www.llnl.gov/tid/Library.html 


\title{
Electrical Resistance Tomography Using Steel Cased Boreholes as Electrodes
}

\author{
Robin L. Newmark*, William Daily and Abelardo Ramirez \\ Lawrence Livermore National Laboratory, Livermore, Ca., 94550
}

\begin{abstract}
Electrical resistance tomography (ERT) using multiple electrodes installed in boreholes has been shown to be useful for both site characterization and process monitoring. In some cases, however, installing multiple downhole electrodes is too costly (e.g., deep targets) or risky (e.g., contaminated sites). For these cases we have examined the possibility of using the steel casings of existing boreholes as electrodes. The first case we investigated used an array of steel casings as electrodes. This results in very few data and thus requires additional constraints to limit the domain of possible inverse solutions. Simulations indicate that the spatial resolution and sensitivity are understandably low but it is possible to coarsely map the lateral extent of subsurface processes such as steam floods. A hybrid case uses traditional point electrode arrays combined with long-conductor electrodes (steel casings). Although this arrangement provides more data, in many cases it results in poor reconstructions of test targets. Results indicate that this method may hold promise for low resolution imaging where steel casings can be used as electrodes.
\end{abstract}

\section{Background}

Electrical resistance tomography (ERT) has been demonstrated to be a useful characterization tool, providing details of the lithostratigraphy between wells (e.g., Newmark et al., 1994). ERT has previously been used to map subsurface processes such as fluid infiltration (Daily et $\mathrm{al}$. , 1992), steam injection and ohnic heating (Ramirez et al., 1993, 1995) by mapping the spatial and temporal changes in soil resistivity resulting from changes in liquid saturation and temperature. It has also been used to monitor the removal of DNAPL chemical during pumping (Newmark et al., 1998). The presence of appreciable amounts of separate-phase, electrically insulating fluids locally increase electrical resistivity. The removal of these fluids during pumping produces a drop in electrical resistivity, as the insulating fluids are displaced by relatively conductive formation fluid.

In general, ERT has been conducted using a cross-borehole geometry, using multiple electrically-isolated electrodes placed in vertical arrays. This geometry has the potential to produce relatively high quality, high resolution images when the aspect ratio of vertical to horizontal spacing is equal to or greater than 1.5:1.0. Typical electrode installations involve multiple electrodes strung on nonconductive casing (e.g., plastic or fiberglass) in conventionallyinstalled boreholes, or as instrumentation strings installed using cone penetrometers. Both designs have been effective in shallow to moderate depths (most recently up to $1300 \mathrm{ft}$ ), but deeper installations require significant and more costly modifications. The ability to obtain ERT images using existing conventional casings as electrodes would increase the applicability of the technique. In this context, we undertook a study to examine the possibility of using the steel casings of existing boreholes as electrodes.

The method of ERT data collection and processing has been described in detail by Ramirez and his colleagues (e.g., Ramirez et al., 1995). The forward and inverse modeling codes are described by LaBrecque et al., (1996). The forward solution is implemented using the finite difference technique with Newman boundary conditions at the ground air interface and Dirichlet boundary conditions along the other faces of the cube. The inverse solution employs an objective function which aims to minimize data misfit and model roughness. The minimization of the objective function is done iterratively.

\section{Case 1: Crosswell ERT}

In the first case, we modeled ERT data acquired using a standard crosswell configuration. The model simulates a typical layered sand and shale sequence (Figure 1). It is composed of a series of various thickness, 40 ohm-m units (sands) imbedded in a $4 \mathrm{ohm}-\mathrm{m}$ matrix (shales). The sand units range in thickness from $2.3 \mathrm{~m}$ to $9.1 \mathrm{~m}$ thick. These $2 \mathrm{D}$ simulations include two ERT electrode strings separated by $30.5 \mathrm{~m}$, each consisting of 30 electrodes. Vertical electrode spacing is set to $4.6 \mathrm{~m}$, so the $2.3 \mathrm{~m}$ thick sand is half the electrode spacing. In all models, there are two pixels per electrode spacing (each pixel is about $2.3 \mathrm{~m}$ square). The modeled region is larger than the image plane alone, so boundary effects are minimized. Synthetic data gencrated using the forward model is inverted, producing an image indicative of a basclinc image one might obtain in the field. In the baseline inversion, the shape of the sands are well represented, even the one whose thickness is only half the electrode separation. The amplitudes are also well reconstructed except for the thinnest sand layer, whose amplitude reflects the averaging expected over the electrode spacing.

We next decrease the resistivity in the sand units, as we simulate the passage of steam through the sands. Over time, the sand units fill with steam, decreasing their resistivity to that of the surrounding shale ( 4 ohm $\mathrm{m}$ ). As the steam fills the sands, the inverted images clearly indicate the location of the steamed region. The location and extent of the region in which resistivities are decreased is well reproduced in all but the thinnest sand, where it appears to be somewhat smeared laterally beyond the zone of change in the model. The absolute value of the difference is well represented in all but the thinnest sand as well. 


\section{ERT using steel cased boreholes as electrodes}

\section{Case 2: Point electrode to casing configuration.}

As an intermediate step toward a pure casing-to-casing configuration, we simulated a hybrid configuration utilizing both point electrodes and vertical casings as long electrodes (Figure 2). These simulations were computed in 3D. We assume two electrode arrays, $23.3 \mathrm{~m}$ apart, with a vertical casing outboard on each side, an additional $23.3 \mathrm{~m}$ out. Two surface electrodes were included, each located an additional 94 m outboard of the two casings. The finite difference mesh width is $1554 \mathrm{~m}$ in the direction co-planar with the casings and electrode arrays, $1508 \mathrm{~m}$ in the direction perpendicular to the image plane, and $786 \mathrm{~m}$ deep. The imaged plane lies in the center. The point electrode arrays are shown schematically in the figure; they are located in the same $98 \mathrm{~m}$ interval as in the first case. The model is only permitted to change between 348 and $446 \mathrm{~m}$; this assumes changes only occur in the pay zone.

In this simulation, we permit the resistivities of the initially $40 \mathrm{ohm}-\mathrm{m}$ sand units to decrease to $10 \mathrm{ohm}-\mathrm{m}$, simulating the progress of steam through the sands over time. The lower sand unit reaches only partway across the image plane. Steam fills from right to left. The decrease in resistivity is apparent in the time progression of the inverted difference images (with respect to baseline) (Figure 2). The location and amplitude of the change is well reproduced between and near the point electrodes. Resolution is lost (the image appears smeared) near the vertical casings.

\section{Case 3: Casing to casing configuration.}

In the casing to casing configuration models, we modeled the electrode array as a simple 9-spot pattern of vertical casings acting as electrodes (Figures 3 and 4). The casings define a square pattern which is $140 \mathrm{~m}$ on a side. Twelve surface electrodes were included, located halfway between each of the nine casings, in the $\mathrm{x}$ and $\mathrm{y}$ directions. The complete model width is $2270.3 \mathrm{~m}$ in both the $\mathrm{x}$ and $\mathrm{y}$ directions, and is $956.2 \mathrm{~m}$ deep. The imaged volume lies in the center, in the depth interval from 348 to $446 \mathrm{~m}$.

We considered two variations of case 3 . In the first, the entire $445 \mathrm{~m}$ long casings were utilized as a "long" electrode (Figure 3 ). In the second, only the lower $70 \mathrm{~m}$ of each casing was energized, simulating a "short" electrode over the lower portion of the casing (Figure 4). This latter configuration reflects engineering considerations for limiting current flow over the upper portion of the casing above the region of interest. In both cases, the model is only permitted to change between 348 and $446 \mathrm{~m}$. As before, the model consists of $40 \mathrm{ohm}-\mathrm{m}$ sands, filling over time with $10 \mathrm{ohm}-\mathrm{m}$ steam, surrounded by a $4 \mathrm{ohm}-\mathrm{m}$ shale. Steam fills from right to left, and only fills part of the volume (plane in and out of the page). All changes are constrained to the lower portion of the model.

In both the "long" and "short" casing to casing simulations, no vertical resolution is available. Ilowever, there is useful horizontal resolution. The resistivity changes across the field are readily apparent, particularly in the difference images. The lateral extent in both the along- and across- steam front directions is well reproduced. The long model predicts a smaller difference amplitude than expected. The short model results in a greater predicted amplitude of the difference, closer to the expected value.

\section{Summary}

We have evaluated the use of metal casings as iong electrodes with which to perform electrical resistance tomography. The results of these simulations suggest that it may be possible to monitor steam flood using this approach. Conventional crosswell ERT provides good lateral and vertical images of resistivity changes resulting from steam progress. In the hybrid case, using both vertical casings and point electrode arrays, overall resolution was degraded with respect to the crosswell electrode string case, yet better than that using casings alone, as expected. Using vertical casings alone, there is distinct signature indicative of the changing resistivity across the field, which is well above the noise level in the simulations. Given these indications, future field work is planned.

\section{Acknowledgments}

This work was funded by the U.S. DOE Natural Gas and Oil Technology Partnership program. We gratefully acknowledge the support of our industrial partncrs, Acra Energy LLC, Chevron Production, Inc. and SteamTech Environmental Services, Inc., in this effort. Work performed under the auspices of the U.S. Department of Energy by the Lawrence Livermore National Laboratory under Contract W-7405-ENG-48.

\section{References}

Daily, W., A. Ramirez, D. LaBrecque and J. Nitao, 1992. Electrical Resistivity Tomography of Vadose Water Movement, Water Resources Research, v. 28, no. 5, 1429-1442.

LaBrecque, D.A., G. Morelli and P. Lundegard, 1996. 3-D electrical resistivity tomography for environmental monitoring, Symposium on the Application of Geophysics to Engineering and Environmental Problems (SAGEEP) '96, Keystone, Co., April 28 - May 2, 723-732.

Newmark, R.L., S. Boyd, W. Daily, R. Goldman, R. Hunter, D. Kayes, K. Kenneally, A. Ramirez, K. Udell, and M. Wilt, 1994. Using geophysical techniques to control in situ thermal remediation, Symposium on the Application of Geophysics to Engineering and Environmental Problems (SAGEEP) '94, Boston, Ma., March 27-31, 195-211. 
ERT using steel cased boreholes as electrodes

Newmark, R.L., W.D. Daily, K.R. Kyle and A. L. Ramirez, 1998. Monitoring DNAPL pumping using integrated geophysical techniques, Journal of Environmental and Engineering Geophysics, v. 3, no.1, 7-14.

Ramirez, A., W. Daily, K. LaBrecque, E. Owen and D. Chesnut, 1993. Monitoring an Underground Steam Injection Process Using Electrical Resistance Tomography, Water Resources Research, v. 29, no. 1.

Ramirez, A., W. Daily and R. L. Newmark, 1995. Electrical resistance tomography for steam injection monitoring and process control, Journal of Environmental and Engineering Geophysics, v. 0, no. 1, p. 39-51.

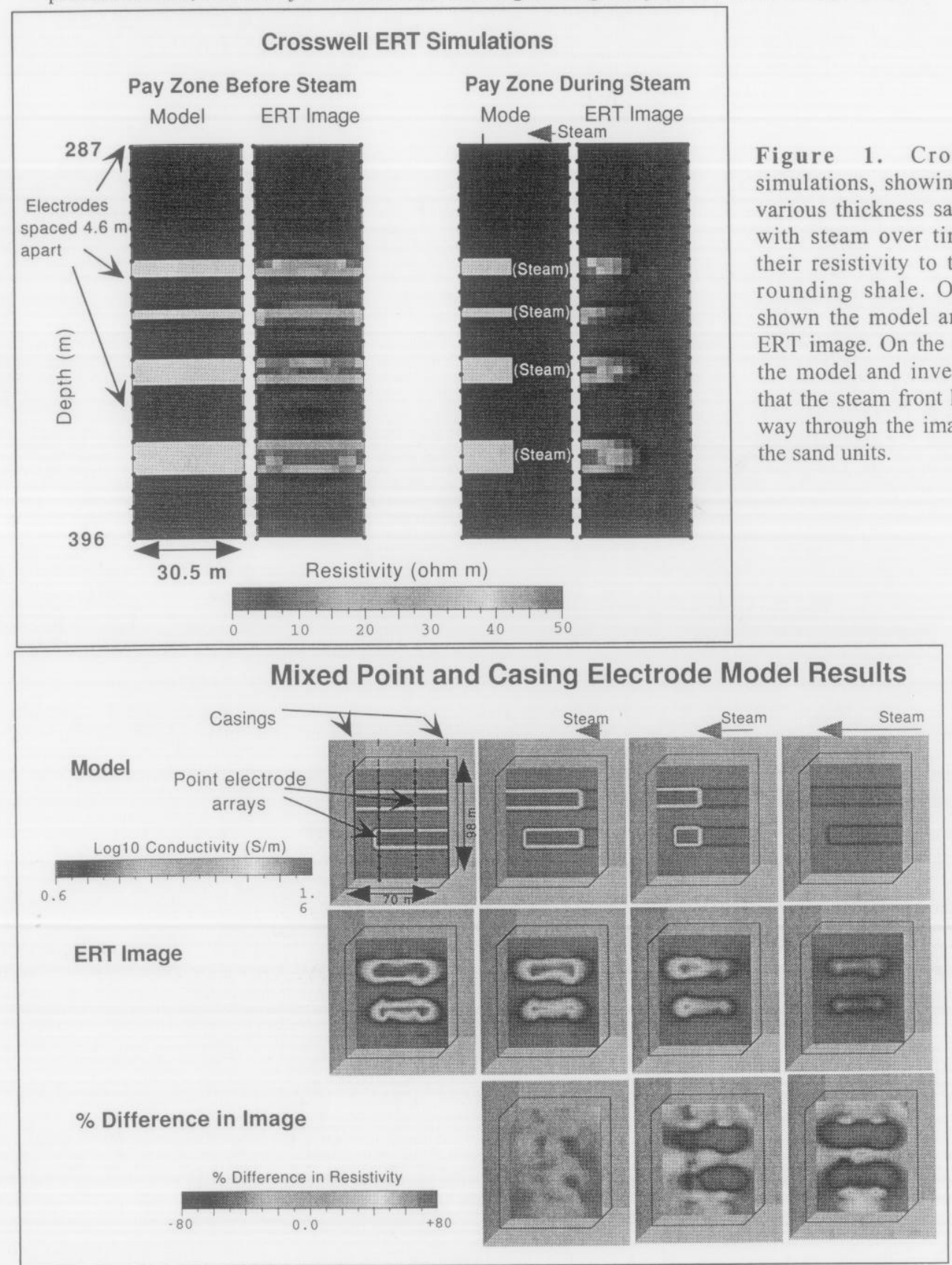

Figure 2. Results of simulating mixed point and casing electrodes. Top: 3D model, with $40 \mathrm{ohm}$ m sands, filling over time with $10 \mathrm{ohm} \mathrm{m}$ steam, surrounded by a $4 \mathrm{ohm} \mathrm{m}$ shale. Steam fills from right to left; the lower sand unit reaches only partway across the image plane. Center: Simulated inversions. Bottom: Difference images (with respect to baseline) over time. 


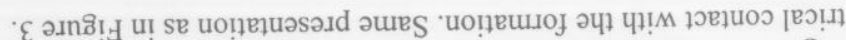

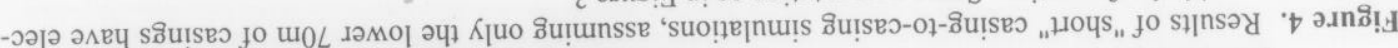

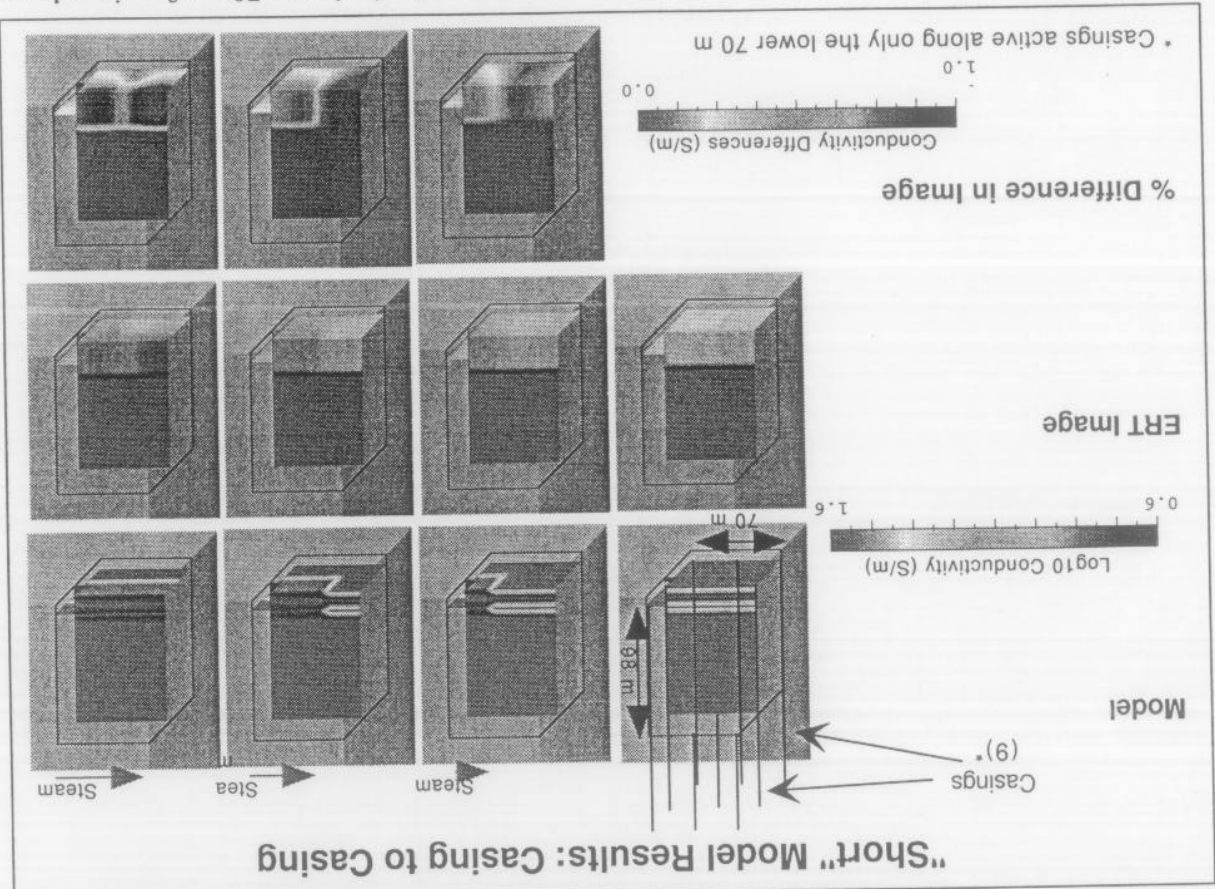

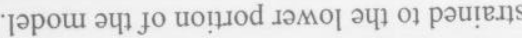

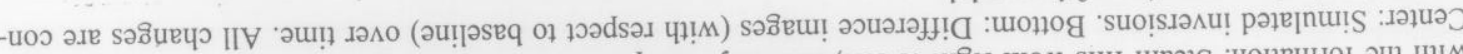

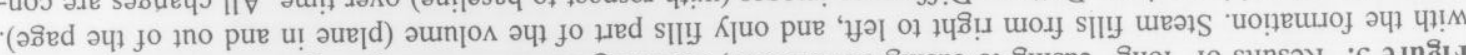

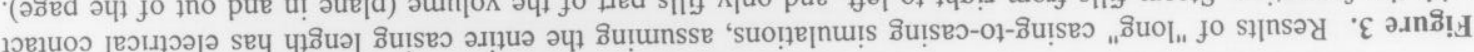

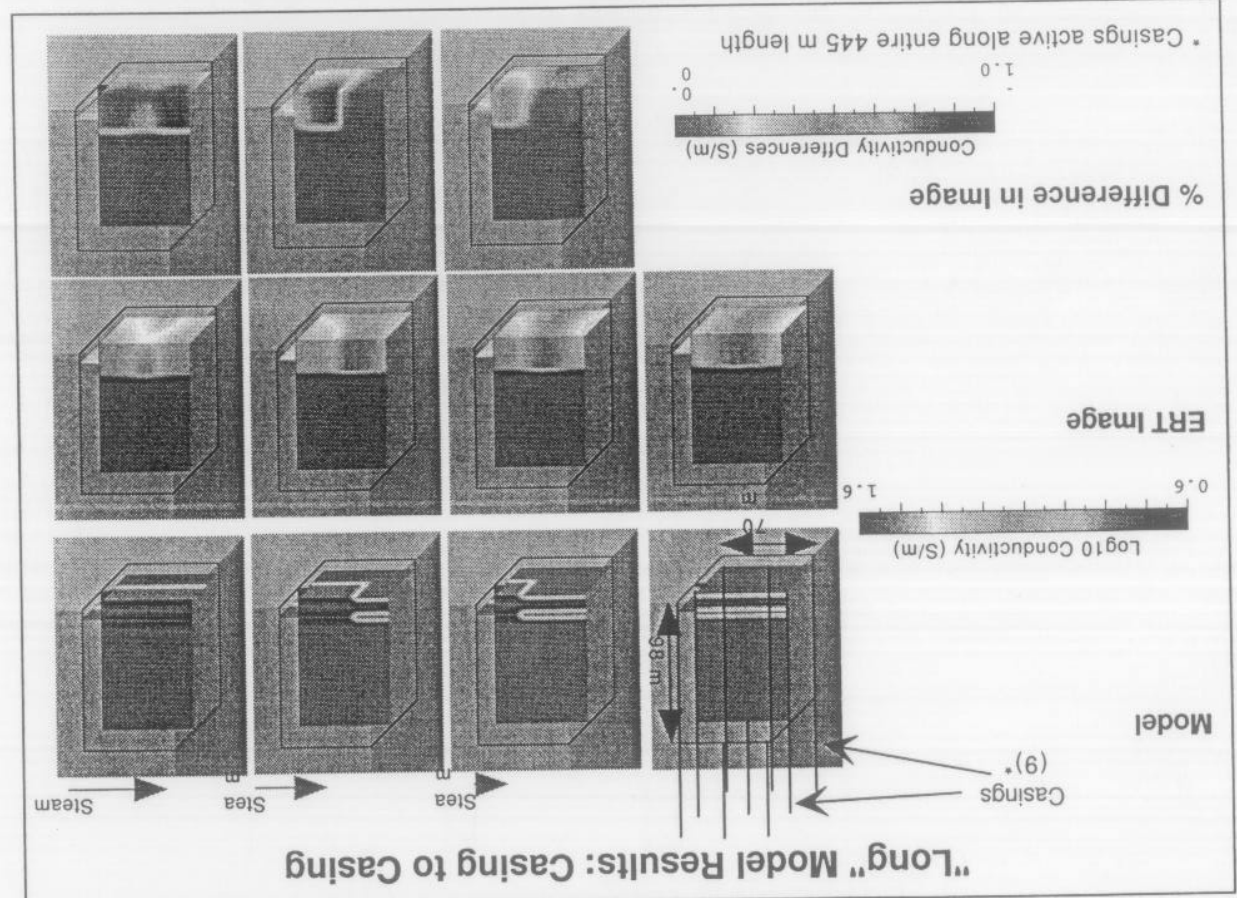

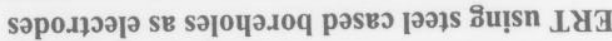

